\begin{tabular}{|l|l|l||}
\hline \multicolumn{2}{|c|}{ PublisherInfo } \\
\hline \hline PublisherName & $:$ & BioMed Central \\
\hline \hline PublisherLocation & $:$ & London \\
\hline \hline PublisherImprintName & $:$ & BioMed Central \\
\hline \hline
\end{tabular}

\title{
Ultrasound diagnosis of pneumothorax
}

\begin{tabular}{|l|l|l||}
\hline \multicolumn{2}{|c|}{ ArticleInfo } \\
\hline \hline ArticleID & $:$ & 4248 \\
\hline \hline ArticleDOI & $:$ & $10.1186 /$ ccf-2000-2641 \\
\hline \hline ArticleCitationID & $:$ & 2641 \\
\hline \hline ArticleSequenceNumber & $:$ & 36 \\
\hline \hline ArticleCategory & $:$ & Paper Report \\
\hline \hline ArticleFirstPage & $:$ & 1 \\
\hline \hline ArticleLastPage & $:$ & 3 \\
\hline \hline & & RegistrationDate : 2000-11-21 \\
ArticleHistory & $:$ & OnlineDate $\quad 2000-11-21$ \\
\hline \hline ArticleCopyright & $:$ & Current Science Ltd2000 \\
\hline \hline ArticleGrants & $:$ & \\
\hline \hline ArticleContext & $:$ & 1305433 \\
\hline \hline
\end{tabular}


Aff1 St Georges Hospital, London, UK

\title{
Keywords
}

\author{
ICU, pneumothorax, ultrasound diagnosis
}

\section{Comments}

It has been suggested that the portable ultrasound machine may become the intensivists' stethoscope in the intensive care unit (ICU), and this paper supports this view. Misdiagnosis of pneumothorax may occur in up to $30 \%$ of intensive care patients when bedside chest radiography is utilised, but the gold standard (CT scan) requires a potentially dangerous transfer of the critically ill patient. Ultrasound can be brought to the bedside and it is already known that the presence of 'lung sliding' or 'comet-tail artifact' confidently excludes pneumothorax. However the specificity of these findings are only $91 \%$ and $77 \%$, respectively. The authors of this study have now shown that the presence of 'lung point' is $100 \%$ specific for pneumothorax, and have therefore developed an algorithm utilising all these ultrasound-based observations in the diagnosis of pneumothorax. Although the authors have not commented on whether these radio-occult pneumothoraces detected by ultrasound required any intervention (chest-drain), presumably the fact that they were aware of their existence would speed up necessary lifesaving intervention if the patient's clinical condition deteriorated.

\section{Introduction}

The value of bedside ultrasound is increasingly being recognised in the ICU, to assist in diagnosis and allow therapeutic interventions to be performed effectively and safely. This study examines the role of ultrasound in the diagnosis of radio-occult pneumothorax in the ICU.

\section{Methods}

- Prospective study of 70 proven consecutive pneumothoraces in 64 ICU patients (60 proven on chest X-ray and the remainder only on CT scan) 
- Control group consisted of 238 lungs in 119 consecutive ICU patients (absence of pneumothorax proven by CT scan). In 17 of these patients pneumothorax was suspected

- Ultrasound examination of all patients to identify the relationship between the presence/absence of 'lung sliding', 'comet-tail artifacts', and 'lung point', and pneumothorax (for description of these terms please see original article)

\section{Results}

In the study group of 66 analyzable pneumothoraces, 'lung sliding' and 'comet-tail artifacts' were absent. 'Lung point' was present in 44 of the pneumothoraces. However, in the control group of 233 analyzable lungs however, 'lung point' was absent, whereas 'lung sliding' was present in 182 and 'comettail' artifacts was present in 146 . The 'lung point' had a sensitivity of $66 \%$ and a specificity of $100 \%$ for the diagnosis of pneumothorax.

\section{References}

1. Lichenstein D, Meziere G, Biderman P, Gepner A: The 'lung point': an ultrasound sign specific to pneumothorax. Intensive Care Med. 2000, 26: 1434-1440.

This PDF file was created after publication. 